\title{
Exploring the predictors of financial impairment in Huntington's disease using the Enroll-HD dataset
}

\author{
Kate L. Harris ${ }^{1} \cdot$ Sarah L. Mason ${ }^{2} \cdot$ Roger A. Barker ${ }^{2,3}$ \\ Received: 22 September 2021 / Revised: 1 December 2021 / Accepted: 2 December 2021 / Published online: 14 February 2022 \\ (c) The Author(s) 2022
}

\begin{abstract}
Objectives Huntington's disease (HD) is a neurodegenerative disease in which cognitive and behavioural symptoms impair the performance of instrumental activities of daily living, including the handling of finances. We sought to determine the prevalence of financial dysfunction in HD, and the demographic and clinical predictors of such impairments.

Methods We analysed longitudinal data for pre-manifest gene carriers and HD patients from the Enroll-HD dataset. Financial dysfunction was determined by finance-related items in the Total Functional Capacity (TFC) and Functional Assessment (FA) scales. A binary logistical regression model was used to investigate the predictive value of demographic and clinical factors for the development of financial dysfunction.

Results Financial impairment was found to be common in HD gene carriers, and over half required financial assistance within 5 years from diagnosis. Cognitive impairment, apathy, unemployment and disease severity predicted financial dysfunction in manifest patients. For pre-manifest patients, the predictors were proximity to disease onset and depression.

Conclusions Loss of financial autonomy is common in HD, and cognitive and psychiatric factors are important in its development. Clinicians must be vigilant to identify patients that may be vulnerable to financial exploitation.
\end{abstract}

Keywords Huntington's disease $\cdot$ Neurodegeneration $\cdot$ Financial impairments $\cdot$ Apathy $\cdot$ Cognitive impairments

\section{Introduction}

Huntington's disease is a neurodegenerative disease characterised by varying degrees of motor, cognitive and psychiatric dysfunction which together impact an individual's functional capacity, including instrumental activities of daily living (iADL) such as housekeeping, driving, and managing medications. One important iADL that has been relatively understudied in HD is financial capacity, which refers to the ability to independently manage one's financial affairs in a manner consistent with one's personal self-interest [1].

Kate L. Harris

kate.harris@ucsf.edu

1 Department of Neurology, University of California San Francisco, San Francisco, United States

2 Department of Clinical Neurosciences, John Van Geest Centre for Brain Repair, E.D. Adrian Building, Forvie Site, Robinson Way, Cambridge CB2 OPY, UK

3 MRC-WT Cambridge Stem Cell Institute, University of Cambridge, Cambridge, UK
Financial capacity is instrumental for independent living and encompasses a variety of domains including practical skills (e.g., counting coins, making purchases), knowledge of facts (e.g., bank account details) and conceptual understanding (e.g., when making investments and exercising financial judgement). Impairments in these abilities renders an individual at risk for financial insecurity and exploitation [2]. There is a large body of evidence to indicate that financial capacity is diminished in neurodegenerative diseases such as MCI [3-5] and Alzheimer's Disease (AD) [2, 6], Parkinson's Disease (PD) [7-9], and frontotemporal dementia (FTD) [10]. Cognitive impairment is an important predictor of financial capacity in these clinical groups [11-15], with difficulties emerging soon after the onset of cognitive decline [16]. Depression also contributes to financial capacity in a non-demented older adult population [17], although the role of depression in financial impairments associated with neurodegeneration is unclear, with some studies showing an association [8, 15, 18], and others not [19-21].

Only a small number of studies have looked to describe financial capacity in HD or understand its underlying factors. Sheppard et al. [22] reported a study of $20 \mathrm{HD}$ patients 
which showed that HD patients were impaired compared to controls on the Advanced Finances Test, which requires participants to pay three bills, deposit a check, and pay off as much of a credit card balance as possible, whilst ensuring that at least $\$ 100$ is left in their account. Performance was found to correlate with cognition, but not with depression.

Another study showed that a loss of financial autonomy is one of the earliest functional impairments to occur in HD with approximately $49 \%$ of HD gene carriers being unable to manage their finances independently prior to receiving a clinical diagnosis [23].

Despite the limited research in this area, self-reported financial impairments in HD have been widely documented through the inclusion of questions on financial autonomy in the Unified Huntington's Disease Rating Scale Total Functional Capacity (TFC) and Functional Assessment (FA) sub-scales [24]. Furthermore, these items are included in Enroll-HD (https://enroll-hd.org), a multinational, longitudinal, natural history study that collects demographic and disease-specific information about HD gene carriers. Whilst these items do not give an in-depth understanding of financial capacity, they do provide a measure of "real-world" performance in HD. Understanding the factors which relate to a reduction in financial capacity measured by the TFC and FA could provide a meaningful insight into the reasons why HD patients have difficulty managing their money so early in the disease and potentially identify ways to better support patients with these problems. Therefore, the current study used the Enroll-HD dataset to identify the prevalence of financial impairments in premanifest and manifest gene carriers, and to interrogate the clinical and demographic predictors of these impairments.

\section{Methods}

\section{Enroll- HD database}

This study used the 4th data cut from the Enroll-HD study (https://www.enroll-hd.org), a longitudinal, observational, multinational study of $\mathrm{HD}$ gene carriers and controls funded by the CHDI Foundation. As part of the study, participants attend a yearly visit during which they undergo motor, cognitive and psychiatric assessment, and complete self-reported measures of function [25]. The assessments from the protocol that were used in this study are detailed in Table 1.

\section{Selection of participants}

Data were available for 20,617 participants comprising of premanifest (pre-HD) and manifest HD gene carriers (mHD) and healthy controls (HC). Participants were excluded from the analysis if they: (1) had not answered the finance-related question in the TFC and FA (2) had a CAG repeat length $>55$ due to an increased likelihood of juvenile onset, (3) were under the age of 18 as these individuals were likely to have different financial responsibilities to older participants, (4) had an International Standard Classification of Education (ISCED) of 0 (meaning they had not attended primary school) and (5) had not completed the MMSE. The HD groups (pre-manifest and manifest) therefore were made up of participants with a CAG repeat length between 39 and 55 . The healthy control group was created by merging the "gene negative carriers" and "family control" groups from the Enroll-HD dataset. A prevalence analysis was conducted on these groups, and then participants were selected for subsequent analyses based on the criteria outlined below.

\section{Demographic and clinical predictors of financial capacity - functional assessment (FA) item}

This analysis consisted of manifest HD gene carriers who reported normal financial functioning on the FA at baseline but impaired functioning at a subsequent visit (i.e., scoring $1=$ normal and then $0=$ impaired, referred to as FAimpaired). These participants were compared to an unimpaired group of manifest gene carriers (FAunimpaired) who reported normal financial management (i.e., scoring "1") at all visits.

\section{Demographic and clinical predictors of financial capacity - total functional capacity (TFC) item}

Three groups were created for analysis of the TFC item; those who transitioned from normal functioning to needing slight assistance at some point during the study (scoring " 3 " then " 2 ", referred to as "TFCmild"), those who transitioned from needing slight assistance to major assistance (scoring " 2 " then "1", referred to as "TFCmoderate") and those who transitioned from needing major assistance to being unable to manage their finances (scoring " 1 " then " 0 ", referred to as "TFCsevere"). We used the same control group for each of these groups, which comprised of manifest patients who scored "3: normal functioning" at all visits (TFCunimpaired). Importantly, this control group was also part of the control group in the FA analysis. However, there was no overlap in the participants included in the impaired groups for the FA or TFC analyses.

Premanifest gene carriers who showed a mild decline in financial management-i.e., from normal functioning (scoring “" 3 ") to needing slight assistance (scoring " 2 "), were defined as a Pre-HDimpaired group and compared to a control group 
Table 1 Enroll-HD assessments used in the analysis

\begin{tabular}{|c|c|c|c|}
\hline Scale & Measurement capturing & Items used & Outcome measure \\
\hline $\begin{array}{l}\text { Unified Huntington's disease rating } \\
\text { scale-total motor score [24] }\end{array}$ & Motor features of HD & All & Total score: $0-124$ \\
\hline $\begin{array}{l}\text { Unified Huntington's disease rating } \\
\text { scale - total functional capacity }\end{array}$ & Daily functioning & $\begin{array}{l}\text { Item 2: What is your level of func- } \\
\text { tioning: finances }\end{array}$ & $\begin{array}{l}0=\text { unable, } 1=\text { major assistance }, \\
2=\text { slight assistance, } 3=\text { normal }\end{array}$ \\
\hline $\begin{array}{l}\text { Unified Huntington's disease rating } \\
\text { scale - functional assessment }\end{array}$ & Daily functioning & $\begin{array}{l}\text { Item 2: Could the participant man- } \\
\text { age his/her finances (monthly) } \\
\text { without any help }\end{array}$ & $1=$ yes or $2=$ no \\
\hline Mini-mental state exam [26] & Global Cognition & All & $\begin{array}{l}\text { Total score: } 0-30 \\
\leq 24=\text { dementia cut-off }\end{array}$ \\
\hline Symbol digit modality (SDMT) [24] & Processing speed & All & $\begin{array}{l}\text { Total number of symbols decoded } \\
\text { in } 90 \mathrm{~s}\end{array}$ \\
\hline $\begin{array}{l}\text { Verbal fluency (VF) (Animal Nam- } \\
\text { ing) [24] }\end{array}$ & Language/executive function & All & $\begin{array}{l}\text { Total animal words generated in } 60 \mathrm{~s} \\
\text { (excluding repetitions or persevera- } \\
\text { tions) }\end{array}$ \\
\hline $\begin{array}{l}\text { Stroop naming, word, interference } \\
\text { [24] }\end{array}$ & Executive function & All & $\begin{array}{l}\text { Total number of blocks verbalised in } \\
45 \mathrm{~s} \text { for each stage (colour naming, } \\
\text { word reading, interference) }\end{array}$ \\
\hline Trail-making A and B [27] & Executive function & All & Time take to complete task \\
\hline $\begin{array}{l}\text { Problem behaviour assessment } \\
\text { (PBA) - short version }\end{array}$ & Psychiatric features of HD & $\begin{array}{l}\text { Item for depression, irritability and } \\
\text { apathy }\end{array}$ & $\begin{array}{l}\text { Frequency: } 0-4 \\
0=\text { never/almost never } 1=\text { seldom } \\
\text { (less than once/week) } 2=\text { some- } \\
\text { times (up to } 4 \text { times a week) } \\
3=\text { frequently (most days } / 5,6 \text { or } 7 \\
\text { times a week) } 4=\text { daily/almost daily } \\
\text { for most (or all) of day } \\
\text { Severity: } 0-4 \\
0=\text { absent } 1=\text { slight, questionable } \\
2=\text { mild (present, not a problem) } \\
3=\text { moderate (symptom causing } \\
\text { problem) } 4=\text { severe (almost intoler- } \\
\text { able for carer) }\end{array}$ \\
\hline
\end{tabular}

of premanifest gene carriers who reported " 3 : normal functioning" at all visits (Pre-HDcontrol).

\section{Data analysis}

\section{Prevalence analysis}

The prevalence of financial impairments for pre-HD, mHD and HCs was calculated by determining the $\%$ of each group who reported financial impairments in the FA or TFC questions at their baseline assessment (i.e., responding "no" on the FA, or $<3$ on the TFC). Prevalence was also calculated for manifest gene carriers stratified by disease duration. Chisquare tests were then conducted to assess whether there were significant differences between the groups.

\section{Demographic and clinical predictors of financial capacity - FA and TFC analysis}

Differences in baseline demographics of control and impaired groups were compared using chi-square tests for nominal data and tests (FA question) or ANOVA (TFC question) for continuous data. For both questions, the demographic and clinical factors that predicted financial decline were determined using a binary logistic regression, whereby group was the dependent variable, and the following variables were added as covariates: age, sex, disease burden score (DBS), CAG repeat length, ISCED, job class, UHDRS motor score, SDMT, verbal fluency, stroop naming, word, interference, apathy, depression, irritability and MMSE. Sequential regression models were performed until best fit of data was achieved. DBS was calculated using the formula $\mathrm{DBS}=\left(\mathrm{CAG}_{\mathrm{n}}-35.5\right) \times$ age [28]

\section{Results}

\section{Prevalence of financial impairment in healthy controls and HD gene carriers}

A total of 3715 controls, 2806 premanifest and 7902 manifest patients were included in the prevalence analysis. As 
measured by the FA item, $0.2 \%$ of healthy controls and $0.1 \%$ of premanifest gene carriers were unable to manage their finances independently on a monthly basis at the baseline visit, whereas $22.8 \%$ of manifest gene carriers were unable to do so $(\chi(1)=0.341, p<0.001$, see Fig. 1). As expected, the prevalence of financial impairment increased with disease duration in manifest patients. For those who had received a diagnosis within the 5 years prior to the baseline visit, $13.8 \%$ were unable to manage their finances, rising to $38.8 \%$ for those who had been diagnosed for $6-10$ years and $55.5 \%$ for those who had been diagnosed for greater than 11 years $(\chi(1)=0.347, p<0.001$, see Fig. 1$)$. In contrast, the TFC financial item yield higher prevalence rates with $1.1 \%$ of healthy controls, $2.2 \%$ of premanifest patients and $62.6 \%$ of manifest patients needing either mild, moderate or major help with finances $(\chi(1)=0.635, p<0.001$, see Fig. 1$)$. Furthermore, these deficits were evident in $60.4 \%$ of those who had been diagnosed for less than 5 years, $79.2 \%$ of those diagnosed for 6-10 years and $85 \%$ of those diagnosed for greater than 11 years $(\chi(1)=0.218 p<0.001)$.

\section{Demographic and clinical predictors of financial capacity - FA analysis}

As shown in Table 2, age and CAG were significantly different between the FAimpaired and FAunimpaired groups, although not to a clinically meaningful level. There was no difference between demographic region or marital status (see supplementary tables 1 and 2), and only 10 patients had experienced a change in marital status between visits, so this was unlikely to contribute to any change in financial autonomy. ISCED scores showed a similar distribution

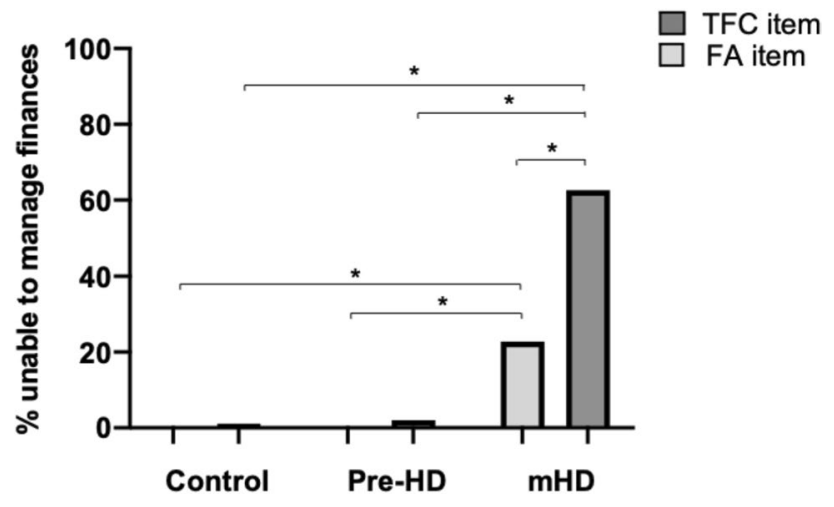

Fig. 1 Graph showing the percentage of patients reporting financial impairments on the FA and TFC items. Chi-square tests were used to compare the prevalence of financial impairments across disease groups. Chi-square tests were also used to compare responses on the FA and TFC items. Mean and standard error of the mean are shown. ${ }^{*} p<0.001$. FA item: controls $n=3715$, premanifest $n=2806$, manifest $n=7902$. TFC item: controls $n=3719$, premanifest $n=2806$, manifest $n=8030$ of educational levels across groups, although the impaired group were significantly less likely to have an undergraduate degree (see supplementary table 3 ). The impaired group was also significantly more likely to be unemployed $(91.7 \%$ vs $66.4 \%, p<0.001$, see Table 2). However, the reasons for unemployment did not differ between the groups, with agerelated retirement being the most common reason for both groups (data not shown).

Importantly, the FAimpaired group had a significantly greater DBS score compared to FAunimpaired (see Table 2), suggesting that they were at a more advanced stage of the disease. Indeed, this group exhibited a more severe disease profile, including greater motor and cognitive impairment, alongside a higher degree of reported apathy (see Table 2). The binary logistical regression indicated that DBS, job class, UHDRS motor score, SDMT, verbal fluency, stroop word, MMSE and apathy are all significant predictors of financial impairment in $\operatorname{HD}\left(\mathrm{x}^{2}(7)=621.976, p<0.001\right.$, see Table 3). Motor scores and apathy were the strongest predictors, with an $\operatorname{Exp}(B)$ of 1.044 and 1.086, respectively. The model explained $51.4 \%$ (Nagelkerke $\mathrm{R}^{2}$ ) of the variance and correctly classified $85 \%$ of cases. Seeing as the impaired group had a significantly lower average MMSE score than the control group (see Table 2), we repeated the analysis including only individuals who scored $>26$ on the MMSE, which is a score indicative of normal cognitive function. A logistic regression analysis showed that when MMSE-determined cognitive impairments are controlled for, UHDRS motor score and apathy predict financial impairments in manifest HD (data not shown).

\section{Demographic and clinical predictors of financial capacity - TFC analysis}

The demographic information for these groups is shown in Table 2. There were no differences between the groups in terms of age or sex, and whilst CAG repeat length was statistically different, it is not likely to make a difference clinically. All three impaired groups had a greater motor, cognitive and apathy scores compared to controls $(p<0.001)$, in addition to greater DBS scores $(p<0.001)$ and higher unemployment $(p>0.05)$. Those reporting moderate or severe impairments had a more severe disease profile compared to those reporting milder impairments, as might be expected,

The results of the binary logistic regression analyses for each group are shown in Table 4. For the mildly impaired group, the results indicated that job class, age, CAG repeat length, DBS and MMSE are all significant predictors of financial impairment in $\operatorname{HD}\left(\mathrm{x}^{2}(6)=138.736 p<0.001\right)$, with the strongest predictor being job class $(\operatorname{Exp}(B)=1.724)$. The model correctly classified $73 \%$ of cases and explained $27.6 \%$ (Nagelkerke $\mathrm{R}^{2}$ ) of the variance, suggesting that other factors not included in the model also contribute to financial 
Table 2 Demographic information per group

\begin{tabular}{|c|c|c|c|c|c|c|c|c|}
\hline & \multicolumn{6}{|l|}{ Manifest HD } & \multirow{2}{*}{\multicolumn{2}{|c|}{$\frac{\text { Pre-HD }}{\text { TFC }}$}} \\
\hline & \multicolumn{2}{|l|}{ FA } & \multicolumn{4}{|l|}{ TFC } & & \\
\hline & $\begin{array}{l}\text { FAunimpaired } \\
(n=1179)\end{array}$ & $\begin{array}{l}\text { FAimpaired } \\
(n=339)\end{array}$ & $\begin{array}{l}\text { TFCunim- } \\
\text { paired } \\
(n=380)\end{array}$ & $\begin{array}{l}\text { TFCmild } \\
(n=233)\end{array}$ & $\begin{array}{l}\text { TFCmoderate } \\
(n=209)\end{array}$ & $\begin{array}{l}\text { TFCsevere } \\
(n=90)\end{array}$ & $\begin{array}{l}\text { PreHDcon- } \\
\text { trol } \\
(n=118)\end{array}$ & $\begin{array}{l}\text { PreHDimpaired } \\
(n=31)\end{array}$ \\
\hline Age (years) & $52(11.7)$ & $54.2(12)^{*}$ & $51.9(11.4)$ & $50.6(11.5)$ & 52.7 (11.7) & $53.4(11.5)$ & $41.4(12.1)$ & $37.3(10.8)$ \\
\hline $\begin{array}{l}\text { CAG repeat } \\
\text { length }\end{array}$ & $43.3(2.9)$ & $44(3.3)^{* * *}$ & $42.8(2.5)$ & $43.8(3)^{* * *}$ & $44(3.4)^{* * *}$ & $43.9(3.3)^{* * *}$ & $42(2.4)$ & $43.8(3.2) * * *$ \\
\hline DBS & 378 (77.8) & $\begin{array}{l}441.4 \\
\quad(146.6)^{* * *}\end{array}$ & 353.9 (72.5) & $\begin{array}{l}406.8 \\
\quad(142.8)^{* * *}\end{array}$ & $\begin{array}{l}416.8(93.2) \\
* * *\end{array}$ & $\begin{array}{l}422.8 \\
(98.7)^{* * * *}\end{array}$ & $250(69.7)$ & $288(83)^{*}$ \\
\hline ISCED & $3.6(1.2)$ & $3.4(1.2)^{*}$ & $3.7(1.2)$ & $3.5(1.3)$ & $3.6(1.2)^{*}$ & $3(1.2)^{* * *}$ & $4.2(1.1)$ & $3.8(1)$ \\
\hline $\begin{array}{l}\text { Job class [\% } \\
\text { unem- } \\
\text { ployed] }\end{array}$ & $\begin{array}{l}3.1(1.3) \\
{[66.4 \%]}\end{array}$ & $\begin{array}{c}3.8(0.7)^{* * *} \\
{[91.7 \%]}\end{array}$ & $\begin{array}{l}2.6(1.4) \\
{[47.6 \%]}\end{array}$ & $\begin{array}{l}2.9(1.3)^{*} \\
{[58.8 \%]}\end{array}$ & $\begin{array}{l}3.6(0.9)^{* * * *} \\
{[85.2 \%]}\end{array}$ & $\begin{array}{l}3.9(0.5)^{* * *} \\
{[92.8 \%]}\end{array}$ & $1.8(1.1)$ & $2.3(1.4)^{*}$ \\
\hline $\begin{array}{l}\text { Sex }(\% \\
\text { female) }\end{array}$ & $50.2 \%$ & $55.2 \%$ & $49.5 \%$ & $44.6 \%$ & $50.7 \%$ & $42.7 \%$ & $65.7 \%$ & $74.2 \%$ \\
\hline $\begin{array}{l}\text { UHDRS } \\
\text { motor score }\end{array}$ & 26.3 (13.6) & $47(16.4)^{* * *}$ & $19.6(10)$ & $\begin{array}{l}28.3 \\
\quad(12.9) * * * \dagger ¥\end{array}$ & $\begin{array}{l}37.1(14.5) \\
* * *+\end{array}$ & $\begin{array}{l}43.2 \\
\quad(16.9) * * *\end{array}$ & $1.1(1.4)$ & $2.3(2) * * *$ \\
\hline SDMT & $30.4(11.4)$ & $16(8.5)^{* * *}$ & $35.6(10.9)$ & $\begin{array}{l}27.3 \\
\quad(10.9)^{* * *} † ¥\end{array}$ & $\begin{array}{l}21.1(9.7)^{* * *} \\
\quad \dagger\end{array}$ & $15.3(8.2)^{* * *}$ & $54(9.4)$ & $46.2(10.5)^{* * *}$ \\
\hline $\begin{array}{l}\text { Verbal Flu- } \\
\text { ency }\end{array}$ & $15.1(5)$ & $9.8(4.3) * * *$ & $16.9(4.9)$ & $\begin{array}{l}14.1(5)^{* * *} \\
\forall ¥\end{array}$ & $\begin{array}{l}11.7(4.7)^{* * *} \\
\dagger\end{array}$ & $9.3(4.4) * * *$ & $22.3(5.8)$ & $20.6(5.6)$ \\
\hline Stroop naming & $50.9(14.7)$ & $\begin{array}{l}32.9 \\
\quad(11.8)^{* * *}\end{array}$ & $57.9(13.7)$ & $\begin{array}{l}47(14.1)^{* * * *} \\
\quad † ¥\end{array}$ & $\begin{array}{l}40.3 \\
\quad(12.4)^{* * *} \dagger\end{array}$ & $\begin{array}{l}31.3 \\
(11.6)^{* * *}\end{array}$ & $75.9(14.1)$ & 73.7 (15.9) \\
\hline Stroop word & $67.2(19.3)$ & $\begin{array}{l}44.2 \\
\quad(15.7)^{* * * *}\end{array}$ & $76.4(17.2)$ & $\begin{array}{l}62.6 \\
\quad(19.6)^{* * *} † ¥\end{array}$ & $\begin{array}{l}54.4 \\
\quad(17.5)^{* * *} \dagger\end{array}$ & $\begin{array}{l}40.9 \\
\quad(15.2)^{* * * *}\end{array}$ & 97.7 (16.4) & $87.8(18.1)^{*}$ \\
\hline $\begin{array}{l}\text { Stroop inter- } \\
\text { ference }\end{array}$ & $29(10.4)$ & $17(8.6)^{* * *}$ & $33.6(9.6)$ & $\begin{array}{l}26.7 \\
\quad(10.1)^{* * *} † ¥\end{array}$ & $\begin{array}{l}20.9(7.9)^{* * *} \\
\dagger\end{array}$ & $16.5(8.8)^{* * *}$ & $44.3(8.9)$ & $42.4(9.7)$ \\
\hline Trail A score & $24.9(1.7)$ & $24.1(4.1)$ & $24.9(1.9)$ & $24.9(1.7) \ddagger$ & $24.8(0.2) \dagger$ & $24(4.3)^{* * *}$ & $25(0)$ & $25(0)$ \\
\hline Trail A time & $52.5(30.2)$ & $\begin{array}{l}95.5 \\
\quad(53.6) * * *\end{array}$ & 46.9 (25.7) & $46.9(24.7) \dagger ¥$ & $\begin{array}{l}72.5 \\
(38.6)^{* * *} \dagger\end{array}$ & $\begin{array}{l}107.8 \\
(59.9)^{* * * *}\end{array}$ & $25.1(8.9)$ & $28.1(10.6)$ \\
\hline Trail B score & $23.7(4.3)$ & $17.8(8.6) * * *$ & $23.9(3.8)$ & $24.1(3.5) \dagger$ & $\begin{array}{l}20.8(7.1)^{* * *} \\
\dagger\end{array}$ & $16.9(8.9)^{* * *}$ & $25(0)$ & $25(0)$ \\
\hline Trail B time & $123.2(64.5)$ & $\begin{array}{l}193.9 \\
(59.8)^{* * *}\end{array}$ & $109(62)$ & $111.2(60.8)$ & $\begin{array}{l}171.2 \\
(65.8) * * *\end{array}$ & $204(61.2)^{* * *}$ & $50.3(20)$ & $57.5(24.9)$ \\
\hline $\begin{array}{l}\text { PBA Irritabil- } \\
\text { ity }\end{array}$ & $3.1(4.6)$ & $3.3(5.1)$ & $2.4(3.8)$ & $2.9(4.1)$ & $3.5(4.8)^{*}$ & $3.1(4.9)$ & $1.1(2.2)$ & $4.5(5.7)^{* * *}$ \\
\hline PBA Apathy & $2.5(3.7)$ & $4.7(4.7)^{* * * *}$ & $1.6(3)$ & $\begin{array}{l}2.4(3.5)^{* * *} \\
\dagger \varnothing\end{array}$ & $3.4(3.9) * * * \neq$ & $4.8(4.6) * * *$ & $0.7(2)$ & $2(3.2)^{*}$ \\
\hline $\begin{array}{l}\text { PBA Depres- } \\
\text { sion }\end{array}$ & $5.1(6.3)$ & $5.5(6.9)$ & $4.5(6)$ & $4.9(5.3)$ & $5.8(6.2)^{*}$ & $5.4(6)$ & $3.2(5.3)$ & $9(8.3) * * *$ \\
\hline MMSE & $26.9(2.6)$ & $23.7(3.9) * * *$ & $27.9(1.9)$ & $26.7(2.6) \dagger ¥$ & $25.4(2.9)^{* * *}$ & $23.3(3.6)^{* * * *}$ & $28.9(1.3)$ & $28(2)^{*}$ \\
\hline
\end{tabular}

$T$ tests were used for the FA and Pre-HD analysis and an ANOVA was used for the TFC analysis. Shows mean and standard deviation in brackets $D B S$ disease burden score, MMSE mini-mental state examination, SDMT symbol digit modality, PBA problem behaviour assessment (PBA) short version; ISCED International standard classification of education

*Indicates a significant difference $(p<0.05)$ when compared with controls for each group

*** Indicates a significant difference $(p<0.001)$ when compared with controls for each group

${ }^{\dagger}$ Indicates a significant difference $(p<0.001)$ when compared with severely impaired patients

${ }_{\sharp}^{\ddagger}$ Indicates a significant difference $(p<0.05)$ when compared with severely impaired patients

$¥$ Indicates a significant difference $(p<0.001)$ when compared with moderately impaired patients

$\notin$ Indicates a significant difference $(p<0.05)$ when compared with moderately impaired patients 
Table 3 Logistical regression model of the predictive role of sociodemographic and baseline clinical variables on financial ability as measured by the FA financial item, for the manifest gene carriers

\begin{tabular}{lrlrlrl}
\hline & \multicolumn{1}{l}{ B } & S.E & \multicolumn{1}{c}{ Wald } & df & \multicolumn{1}{l}{ Sig } & $\operatorname{Exp}(\mathrm{B})$ \\
\hline DBS & 0.002 & 0.001 & 10.132 & 1 & 0.001 & 1.002 \\
Job class & -0.976 & 0.323 & 9.125 & 1 & 0.003 & 0.377 \\
Motor score & 0.043 & 0.006 & 49.673 & 1 & $<0.001$ & 1.044 \\
SDMT & -0.076 & 0.013 & 35.693 & 1 & $<0.001$ & 0.927 \\
Verbal fluency & -0.067 & 0.022 & 9.059 & 1 & 0.003 & 0.935 \\
MMSE & -0.071 & 0.029 & 6.091 & 1 & 0.014 & 0.932 \\
PBA-Apathy & 0.083 & 0.018 & 20.495 & 1 & $<0.001$ & 1.086 \\
\hline
\end{tabular}

$D B S$ disease burden score, $M M S E$ mini-mental state examination, SDMT symbol digit modality, $P B A$ Problem behaviour assessment (PBA) - short version

FAimpaired $n=339$; FAunimpaired $n=1179$

\begin{tabular}{lllllll}
\hline & B & S.E & Wald & df & Sig & Exp(B) \\
\hline Mildly impaired & & & & & & \\
Age & -0.108 & 0.026 & 17.41 & 1 & $<0.001$ & 0.898 \\
CAG repeat length & -0.514 & 0.148 & 12.113 & 1 & 0.001 & 0.598 \\
Job class & 0.544 & 0.208 & 6.865 & 1 & 0.009 & 1.724 \\
Motor score & 0.059 & 0.009 & 41.826 & 1 & $<0.001$ & 1.061 \\
DBS & 0.014 & 0.003 & 19.442 & 1 & $<0.001$ & 1.014 \\
MMSE & -0.17 & 0.044 & 15.282 & 1 & $<0.001$ & 0.843 \\
Moderately impaired & & & & & & \\
Job class & -1.531 & 0.342 & 20.064 & 1 & $<0.001$ & 0.216 \\
Motor score & 0.076 & 0.011 & 47.303 & 1 & $<0.001$ & 1.079 \\
Stroop interference & -0.107 & 0.017 & 40.472 & 1 & $<0.001$ & 0.899 \\
MMSE & -0.193 & 0.056 & 11.647 & 1 & 0.001 & 0.825 \\
Severely impaired & & & & & & \\
Job class & -4.695 & 1.064 & 19.472 & 1 & $<0.001$ & 0.009 \\
Motor score & 0.095 & 0.019 & 26.545 & 1 & $<0.001$ & 1.1 \\
Stroop word & -0.109 & 0.016 & 45.983 & 1 & $<0.001$ & 0.897 \\
PBA- apathy & 0.231 & 0.056 & 17 & 1 & $<0.001$ & 1.259 \\
\hline
\end{tabular}

$D B S$ disease burden score, $M M S E$ mini-mental state examination

TFCunimpaired $(n=380)$; TFCmild $(n=233)$; TFCmoderate $(n=209)$; TFCsevere $(n=90)$
Table 4 Logistical regression model of the predictive role of sociodemographic and baseline clinical variables on financial ability as measured by the TFC financial item, for the manifest gene carriers impairment in these patients. For the moderately impaired group, job class, UHDRS motor score, stroop interference and MMSE score were significant predictive factors $\left(\mathrm{x}^{2}\right.$ $(4)=349.129 p<0.001)$, with employment status being the strongest predictor $(\operatorname{Exp}(B)=1.102)$. This model explained $62 \%$ (Nagelkerke $\mathrm{R}^{2}$ ) of the variance and correctly classified $85 \%$ of cases. Finally, for the severely impaired group, job class, UHDRS motor score, stroop word, and apathy were the significant predictive factors of financial impairment $\left(x^{2}(4)=317.794 p<0.001\right)$. The model explained $79.2 \%$ (Nagelkerke $\mathrm{R}^{2}$ ) of the variance and correctly classified $95 \%$ of cases, with apathy being the strongest predictor $(\operatorname{Exp}(\mathrm{B})=1.259)$.

\section{Factors that drive financial impairment in premanifest HD}

A small group of premanifest gene carriers $(n=32,0.9 \%)$ reported a mild decline in financial functioning on the TFC question (from normal functioning to needing slight assistance). Compared to a control group of premanifest gene carriers who reported that they were managing finances normally, these participants had a significantly greater DBS score $(p<0.05)$, and also performed significantly worse on the SDMT $(p<0.001)$ and stroop word tasks $(p<0.05$, see Table 2$)$. Furthermore, they had significantly greater apathy, irritability, and depression scores, with the latter being particularly high. The binary logistical regression indicated that motor score, SDMT and depression were significant predictors of financial impairment in these 
Table 5 Logistical regression model of the predictive role of sociodemographic and baseline clinical variables on financial ability as measured by the TFC financial item, for the premanifest gene carriers

\begin{tabular}{lllllll}
\hline & B & S.E & Wald & df & Sig & Exp $(B)$ \\
\hline Motor score & 0.327 & 0.131 & 6.211 & 1 & 1 & 0.013 \\
SDMT & -0.053 & 0.024 & 4.790 & 1 & 0.029 & 0.949 \\
Depression & 0.103 & 0.034 & 9.023 & 1 & 0.003 & 1.108 \\
\hline
\end{tabular}

SDMT Symbol digit modalities test

PreHDcontrol $(n=118)$; PreHDimpaired $(n=31)$

participants $\left(\mathrm{x}^{2}(3)=31.780, p<0.001\right.$, see Table 5$)$. The model explained $30 \%$ (Nagelkerke $\mathrm{R}^{2}$ ) of the variance and correctly classified $82.6 \%$ of cases.

\section{Discussion}

Using a large HD dataset (ENROLL-HD) we found that financial impairment is a significant problem in HD, with $60 \%$ of patients reporting that they need assistance with their finances within 5 years of disease onset. We also show that this loss of financial autonomy is associated with specific cognitive and psychiatric impairments in addition to advancing disease and can be seen in premanifest patients approaching disease onset as recorded by DBS.

\section{Motor impairments}

The UHDRS total motor score predicted financial impairment in every financially impaired group included in the study. This differs from the study by Sheppard et al. 2016, which found no correlation between UHDRS total motor score and financial dysfunction in HD, although the sample size of that study may have been too small to detect such a relationship. Importantly, UHDRS total motor score can be considered as a surrogate marker of disease stage in HD, and therefore its significance in the current study may reflect advancing disease as opposed to a direct influence of motor problems. Indeed, disease progression correlates with financial impairment in other neurodegenerative diseases such as AD [2], and in our study DBS was also a predictor of financial impairment. Understanding which specific aspects of disease progression drive impairments in financial capacity in HD is essential and we will consider some of these factors below.

\section{Cognitive impairments}

We found that cognitive dysfunction was associated with a decrease in financial autonomy at all stages of the disease, which is consistent with the wider literature in other neurodegenerative diseases [29] including a previous smaller study in HD [22]. Interestingly, the profile of cognitive deficits was different when looking at financial capacity using the TFC or FA. It remains unclear why this was the case, but one possibility is that the questions were testing different aspects of financial capacity, as discussed in more detail below. Studies in AD have found a correlation between financial impairment and executive function as measured by the trail B test $[7,11,15]$, however, performance on this task did not predict financial impairment in the current study. This is perhaps surprising given that executive dysfunction is a cardinal feature of HD [30].

In terms of premanifest gene carriers, the financially impaired group showed a similar cognitive profile to controls, although they did exhibit lower scores on the SDMT and stroop word task, with the former predicting financial impairment. The SDMT has been shown to be an early predictor of disease onset in premanifest HD [31], therefore it could reflect disease onset in this analysis (i.e., with participants showing reduced financial capacity being closer to disease onset than those who remain autonomous). Interestingly, the SDMT is associated with activation in several brain regions known to be affected early in HD such as the caudate nucleus, frontal lobe, insula and posterior cingulate [32], which are also regions implicated in financial decision making [33, 34]. However, future work will be needed to investigate this further.

It is important to note that although the cognitive tasks included in Enroll-HD provide a general measure of cognitive function, they could not be used to ascertain which specific cognitive domains are driving financial impairments in HD (i.e., working memory, attention, arithmetic skills, etc.), and, therefore, this should be a focus of future research.

\section{Psychiatric impairments}

It seems plausible that psychiatric impairments such as depression, apathy and irritability would make it more difficult for HD gene carriers to manage their money independently. However, there have been mixed findings with regard to the role of depression in financial impairments in neurodegenerative diseases $[8,15,18-21]$. In the current study, self-reported apathy was found to 
be significantly higher in financially impaired manifest patients compared to financially capable controls, whilst irritability and depression scores did not differ between the two groups. Furthermore, apathy predicted financial impairments in patients unable to manage their finances, but not in patients who needed mild or moderate assistance, indicating that apathy may contribute to the later stages of financial decline. A better understanding of this relationship, including the extent to which the apathy at this stage in the disease is a consequence of anti-dopaminergic medication may provide insights into ways in which financial capacity can be managed in manifest HD.

We found that premanifest gene carriers who exhibited financial impairments had higher levels of depression, apathy and irritability compared to controls, with depression predicting such impairments in this small group of individuals. Depression is prevalent in the earlier stages of the HD [35] and in some cases can be responsive to medication such as SSRIs. Going forward it will be important to establish whether treating depression can also reduce the financial impairment experienced in the premanifest stage of HD.

\section{Employment status}

The current study showed that financially impaired patients were significantly more likely to be unemployed than financially capable ones (91.7\% vs $66.4 \%$ ), although it is not possible to deduce the relationship between these two iADLs from the current study. However, it is noteworthy that half of financially impaired patients reported being non-employed due to age-related retirement rather than ill health. Therefore, it is possible that the change of environment associated with retirement had a negative impact on financial management for these individuals but further work will be needed to explore this relationship.

\section{Limitations}

A major disadvantage of the current study was the lack of detail in the financial questions included in the TFC and FA. Future studies should therefore interrogate which specific aspects of financial management were problematic for HD patients, for example, counting coins, using an ATM, making transfers/investments, etc., [2]. Furthermore, participants were likely to have had differing degrees of financial responsibility from the outset, meaning that financial impairments may be easier to detect in some participants. In addition, there are intrinsic drawbacks of self-report assessments, including a lack of insight, psychiatric symptoms, and cognitive impairment. We and others have shown that HD patients underestimate motor and cognitive impairments when compared to reports by their companions [36-38], and the same may be the case for financial impairments in the current study. Not every participant in the study will have had a companion to assist with the answering of questions and so their responses may be less accurate than those that did. Finally, whilst we were able to identify some of the factors which contribute to financial dysfunction, we were unable to elucidate the specific aspects of motor or cognitive deficits driving the impairments as the repertoire of test results available to us was limited. This should be a focus for future research.

\section{Conclusion}

The large sample size of the current study has enabled us to estimate the prevalence of financial impairments in HD, which is important given that the ability to manage finances is an essential part of independent living [1]. The fact that almost $1 / 3$ of manifest gene carriers cannot manage their finances renders them at risk of financial insecurity and financial abuse [2]. The results from this study will enable clinicians to recognise potentially vulnerable patients whilst also raising more fundamental questions as to the basis of that deficit and how this can best be managed and/or treated.

Supplementary Information The online version contains supplementary material available at https://doi.org/10.1007/s00415-021-10929-4.

Acknowledgements We would like to thank all participants and funders of Enroll-HD. This research was supported by the NIHR Cambridge Biomedical Research Centre (BRC-1215-20014) and the Huntington's disease Association (RG90732). The views expressed are those of the author(s) and not necessarily those of the NIHR or the Department of Health and Social Care'.

Author contributions $\mathrm{KH}$ execution of statistical analysis, writing of the first draft. SM conceptualisation of project, review and critique of statistical analysis, review and critique of the manuscript. RB conceptualisation of project, review and critique of the manuscript.

Funding This research was supported by the NIHR Cambridge Biomedical Research Centre (BRC-1215-20014).

Availability of data and material The Enroll-HD database is available upon request from (https://www.enroll-hd.org).

Code availability Not applicable.

\section{Declarations}

Conflicts of interest The authors have no financial conflicts of interest.

Ethical approval The Enroll-HD study is approved by Wales Rec 1 .

Consent to participate All participants involved in the Enroll-HD study sign a consent form.

Consent for publication Not applicable.

Open Access This article is licensed under a Creative Commons Attribution 4.0 International License, which permits use, sharing, 
adaptation, distribution and reproduction in any medium or format, as long as you give appropriate credit to the original author(s) and the source, provide a link to the Creative Commons licence, and indicate if changes were made. The images or other third party material in this article are included in the article's Creative Commons licence, unless indicated otherwise in a credit line to the material. If material is not included in the article's Creative Commons licence and your intended use is not permitted by statutory regulation or exceeds the permitted use, you will need to obtain permission directly from the copyright holder. To view a copy of this licence, visit http://creativecommons. org/licenses/by/4.0/.

\section{References}

1. Marson DC, Kerr DL, Mclaren DG (2016) Financial decisionmaking and capacity in older adults. Handbook of the psychology of aging. Academic Press, pp 361-388

2. Marson DC (2001) Loss of financial competency in dementia: conceptual and empirical approaches. Aging Neuropsychol Cogn 8(3):164-181

3. Griffith HR, Belue K, Sicola A, Krzywanski S, Zamrini E, Harrell L, Marson DC (2003) Impaired financial abilities in mild cognitive impairment: a direct assessment approach. Neurology 60(3):449-457

4. Martin RC, Gerstenecker A, Triebel KL, Falola M, McPherson T, Cutter G, Marson DC (2019) Declining financial capacity in mild cognitive impairment: a six-year longitudinal study. Arch Clin Neuropsychol 34(2):152-161

5. Triebel KL, Martin R, Griffith HR, Marceaux J, Okonkwo OC, Harrell L, Clark D, Brockington J, Bartolucci A, Marson DC (2009) Declining financial capacity in mild cognitive impairment: a 1-year longitudinal study. Neurology 73(12):928-934

6. Nicholas LH, Langa KM, Bynum JP, Hsu JW (2021) Financial presentation of Alzheimer disease and related dementias. JAMA Intern Med 181(2):220-227

7. Giannouli V, Stamovlasis D, Tsolaki M (2018) Exploring the role of cognitive factors in a new instrument for elders' financial capacity assessment. J Alzheimers Dis 62(4):1579-1594

8. Giannouli V, Tsolaki M (2019) Depression and financial capacity assessment in Parkinson's disease with dementia: overlooking an important factor? Psychiatrike $=$ Psychiatriki 30(1):66-70

9. Martin RC, Triebel KL, Kennedy RE, Nicholas AP, Watts RL, Stover NP, Brandon M, Marson DC (2013) Impaired financial abilities in Parkinson's disease patients with mild cognitive impairment and dementia. Parkinsonism Relat Disord 19(11):986-990

10. Gill S, Blair M, Kershaw M, Jesso S, MacKinley J, Coleman K, Pantazopoulos K, Pasternak S, Finger E (2019) Financial capacity in frontotemporal dementia and related presentations. J Neurol 266(7):1698-1707

11. Sherod MG, Griffith HR, Copeland J, Belue K, Krzywanski S, Zamrini EY, Harrell LE, Clark DG, Brockington JC, Powers RE, Marson DC (2009) Neurocognitive predictors of financial capacity across the dementia spectrum: normal aging, mild cognitive impairment, and Alzheimer's disease. J Int Neuropsychol Soc 15(2):258-267

12. Earnst KS, Wadley VG, Aldridge TM, Steenwyk AB, Hammond AE, Harrell LE, Marson DC (2001) Loss of financial capacity in Alzheimer's disease: the role of working memory. Aging Neuropsychol Cogn 8(2):109-119

13. Bassett SS (1999) Attention: neuropsychological predictor of competency in Alzheimer's disease. J Geriatr Psychiatry Neurol 12(4):200-205
14. Okonkwo OC, Wadley VG, Griffith HR, Ball K, Marson DC (2006) Cognitive correlates of financial abilities in mild cognitive impairment. J Am Geriatr Soc 54(11):1745-1750

15. Niccolai LM, Triebel KL, Gerstenecker A, McPherson TO, Cutter GR, Martin RC, Marson DC (2017) Neurocognitive predictors of declining financial capacity in persons with mild cognitive impairment. Clin Gerontol 40(1):14-23

16. Pérès K, Helmer C, Amieva H, Orgogozo JM, Rouch I, Dartigues JF, Barberger-Gateau P (2008) Natural history of decline in instrumental activities of daily living performance over the 10 years preceding the clinical diagnosis of dementia: a prospective population-based study. J Am Geriatr Soc 56(1):37-44

17. Morin RT, Gonzales MM, Bickford D, Catalinotto D, Nelson C, Mackin RS (2019) Impaired financial capacity in late-life depression: revisiting associations with cognitive functioning. J Int Neuropsychol Soc 25(10):1088-1093

18. Pirogovsky E, Martinez-Hannon M, Schiehser DM, Lessig SL, Song DD, Litvan I, Filoteo JV (2013) Predictors of performancebased measures of instrumental activities of daily living in nondemented patients with Parkinson's disease. J Clin Exp Neuropsychol 35(9):926-933

19. Mahurin RK, DeBettignies BH, Pirozzolo FJ (1991) Structured assessment of independent living skills: preliminary report of a performance measure of functional abilities in dementia. J Gerontol 46(2):P58-P66

20. Martin R, Griffith HR, Belue K, Harrell L, Zamrini E, Anderson B, Anderson A, Marson D (2008) Declining financial capacity in patients with mild Alzheimer disease: a one-year longitudinal study. Am J Geriatr Psychiatry 16(3):209-219

21. Arcara G, Burgio F, Benavides-Varela S, Toffano R, Gindri P, Tonini E, Meneghello F, Semenza C (2017) Numerical activities of daily living-financial (NADL-F): a tool for the assessment of financial capacities. Neuropsychol Rehabil. https://doi.org/10. 1080/09602011.2017.1359188

22. Sheppard DP, Pirogovsky-Turk E, Woods SP, Holden HM, Nicoll DR, Filoteo JV, Corey-Bloom J, Gilbert PE (2017) Everyday functioning in Huntington's disease: a laboratory-based study of financial management capacity. Appl Neuropsychol Adult 24(2):176-182

23. Beglinger LJ, O'Rourke JJ, Wang C, Langbehn DR, Duff K, Paulsen JS, Huntington Study Group Investigators (2010) Earliest functional declines in Huntington disease. Psychiatry Res 178(2):414-418

24. Kremer HPH, Hungtington Study Group (1996) Unified Huntington's disease rating scale: reliability and consistency. Mov Disord $11: 136-142$

25. Landwehrmeyer GB, Fitzer-Attas CJ, Giuliano JD, Gonçalves N, Anderson KE, Cardoso F, Ferreira JJ, Mestre TA, Stout JC, Sampaio C (2017) Data analytics from Enroll-HD, a global clinical research platform for Huntington's disease. Mov Disord Clin Pract 4(2):212-224

26. Folstein MF, Folstein SE, McHugh PR (1975) "Mini-mental state": a practical method for grading the cognitive state of patients for the clinician. J Psychiatr Res 12(3):189-198

27. Tombaugh TN (2004) Trail making test A and B: normative data stratified by age and education. Arch Clin Neuropsychol 19(2):203-214

28. Langbehn DR, Brinkman RR, Falush D, Paulsen JS, Hayden $\mathrm{MR}$, an International Huntington's Disease Collaborative Group (2004) A new model for prediction of the age of onset and penetrance for Huntington's disease based on CAG length. Clin Genet 65(4):267-277

29. Bangma DF, Tucha O, Tucha L, De Deyn PP, Koerts J (2021) How well do people living with neurodegenerative diseases manage their finances? A meta-analysis and systematic review on the 
capacity to make financial decisions in people living with neurodegenerative diseases. Neurosci Biobehav Rev 127:709-739

30. Lawrence AD, Sahakian BJ, Hodges JR, Rosser AE, Lange KW, Robbins TW (1996) Executive and mnemonic functions in early Huntington's disease. Brain 119(5):1633-1645

31. Tabrizi SJ, Scahill RI, Owen G, Durr A, Leavitt BR, Roos RA, Borowsky B, Landwehrmeyer B, Frost C, Johnson H, Craufurd D, Reilmann R, Stout JC, Langbehn DR, TRACK-HD Investigators (2013) Predictors of phenotypic progression and disease onset in premanifest and early-stage Huntington's disease in the TRACKHD study: analysis of 36-month observational data. Lancet Neurol 12(7):637-649

32. Matías-Guiu JA, Cortés-Martínez A, Montero P, Pytel V, MorenoRamos T, Jorquera M, Yus M, Arrazola J, Matías-Guiu J (2018) Identification of cortical and subcortical correlates of cognitive performance in multiple sclerosis using voxel-based morphometry. Front Neurol 9:920
33. Frydman C, Camerer CF (2016) The psychology and neuroscience of financial decision making. Trends Cogn Sci 20(9):661-675

34. Knutson B, Rick S, Wimmer GE, Prelec D, Loewenstein G (2007) Neural predictors of purchases. Neuron 53(1):147-156

35. Craufurd D, Thompson JC, Snowden JS (2001) Behavioral changes in Huntington disease. Neuropsychiatry Neuropsychol Behav Neurol 14(4):219-226

36. Ho AK, Robbins AO, Barker RA (2006) Huntington's disease patients have selective problems with insight. Mov Disord 21(3):385-389

37. Deckel AW, Morrison D (1996) Evidence of a neurologically based "denial of illness" in patients with Huntington's disease. Arch Clin Neuropsychol 11(4):295-302

38. Hoth KF, Paulsen JS, Moser DJ, Tranel D, Clark LA, Bechara A (2007) Patients with Huntington's disease have impaired awareness of cognitive, emotional, and functional abilities. J Clin Exp Neuropsychol 29(4):365-376 